\title{
ANÁLISE DO INSTRUMENTO UTILIZADO NO PROCESSO DE AVALIAÇÃO \\ DE DESEMPENHO DA EQUIPE DE ENFERMAGEM DO HOSPITAL UNIVERSITÁRIO DA USP*
}

\author{
ANALYSIS OF THE INSTRUMENT AT THE PROCESS NURSING STAFF'S \\ PERFOMANCE EVALUATION AT THE UNIVERSITY HOSPITAL OF USP
}

\author{
Maria Madalena Januário Leite (coordenadora)** \\ Dulce Maria Rosa Gualda*** \\ Vera Lucia Mira Gonçalves ***** \\ Valéria Castilho** \\ Diley Cardoso Franco Ortiz***** \\ Fernanda Maria Togeiro Fugulin****

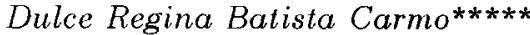 \\ Teresa Cristina Manrique Coan****
}

LEITE, J.M.M. et al. Análise do instrumento utilizado no procє sso de avaliação de desempenho da equipe de enfermagem do Hospital Universitário da USP. Rev. Esc.Enf.USP, v.33, n.3, p.265-78, set 1999.

\section{RESUMO}

Este trabalho teve como objetivos verificar se os avaliadores e avaliados seguem os critérios operacionais que norteiam o processo de avaliação de desempenho da equipe de enfermagem do $H U$, identificar as graduações atribuidas aos prognosticadores obrigatórios e optativos pelos avaliadores e avaliados; identificar os prognosticadores optativos escolhidos pelos avaliadores e avaliados e instrumentalizar os pesquisadores para a reformulação do processo de avaliação de desempenho da equipe de enfermagem do HU. Os resultados mostraram que apesar das diferentes posições e categorias funcionais dentro do processo de avaliasão de desempenho, houve um alto grau de concordância entre avaliadores e avaliados, tanto na atribuição de valores, como na seleção de prognosticadores optativos. Este fato demonstra que há uma coerência no processo de avaliação de desempenho da equipe de enfermagem do HU, revelando que avaliadores e avaliados compartilham dos mesmos pressupostos quanto a finalidade e importância dos prognosticadores inseridos no instrumento de avaliação de desempenho.

UNITERMOS: Avaliação de desempenho. Administração de Recursos Humanos. Administração em enfermagem.

\section{ABSTRACT}

The aim of this study was to check if the evaluators and evaluated follow the operacional criterion that direct the nursing staffs evaluation of $\mathrm{HU}$; to the identify the graduation confered to obrigatory and optional forecasters by evaluators and evaluated; to indentify the optional forecaster chosen by evaluators and evaluated and prepare the researches to a change at the process of nursing staff's evaluation of $H U$. The results showed that different functional categories had similar points of view; there were high level of agreement between them; both values atribuition as optional forecaster selection. It's demonstraded that there's coherence at the process of nursing staff's perfomance evaluation, the evaluators shaves with evaluated the same pre-supposition about the purpose and importance of the forecasters insert in the instrument of perfomance evaluation.

UNITERMS: Nursing administration.

\footnotetext{
* Trabalho realizado com o apoio da Fundação de Amparo à Pesquisa do Estado de São Paulo (FAPESP)

** Enfermeira. Prof́. Doutor da Escola de Enfermagem da Universidade de São Paulo.

*** Enfermeira. Prof.Doutor da Escola de Enfermagem da Universidade de São Paulo.Diretora do Departamento de Enfermagem do Hospital Universitário da USP.

**** Enfermeira do Hospital Universitário da USP. Mestre em Enfermagem.

${ }^{* * * *}$ Enfermeira do Hospital Universitário da USP.
} 
A presente pesquisa é parte integrante de uma proposta de reorganização da área de Recursos Humanos do Departamento de Enfermagem, do Hospital Universitário da Universidade de São Paulo.

O desenvolvimento dessa proposta reveste-se de importância face às mudanças, que vem sendo preconizadas, no gerenciamento de recursos humanos e a necessidade sentida pelos profissionais, envolvidos nesse processo, de estarem revendo suas práticas gerenciais.

A finalidade dessa pesquisa foi a de analisar os registros das avaliações de desempenho dos elementos da equipe de enfermagem do referido Hospital, cujos resultados auxiliarão no aprimoramento do modelo de avaliação de desempenho que está sendo desenvolvido e das políticas e programas de desenvolvimento de pessoal do Departamento de Enfermagem.

Este projeto foi realizado em conjunto com as docentes da disciplina de Administração Aplicada à Enfermagem da Escola de Enfermagem da Universidade de São Paulo e as enfermeiras do Departamento de Enfermagem do Hospital Universitário da Universidade de São Paulo, dentro de uma proposta de desenvolvimento de pesquisa interinstitucional.

\section{INTRODUÇÃO}

A globalização da economia e das informações tem levado as instituições a repensarem a sua forma de gerenciamento, para serem mais competitivas, com isso a gestão de recursos humanos também tem sido desafiada a modificar a sua atuação.

De acordo com PINTO (1995) esse cenário exige das organizações não apenas intuição, mas principalmente informações para as tomadas de decisões. Para este autor o sucesso e sobrevivência das instituições dependerá das informações, as quais são utilizadas para a produção de bens e de serviços, ampliando o bem estar da população. LUCENA (1992) aponta que as decisões são tomadas e praticadas por pessoas, portanto são as pessoas que promovem as mudanças, sendo evidente o impacto da competência na produtividade das organizações.

Assim o gerenciamento do desempenho humano no trabalho é um dos focos de atenção do processo de gestão de recursos humanos, pois seus resultados influenciam as demais fases desse processo, isto é, recrutamento, seleção, treinamento e supervisão dos trabalhadores de uma determinada organização.

LUCENA (1992) ao fazer uma retrospecitva histórica do processo de avaliação de desempenho, mostra que a mesma é tão antiga quanto o homem. Os jesuítas já eram submetidos a processos de avaliação sobre a sua atuação e os registros históricos apontam o rigoroso sistema de avaliação adotado pela Igreja Católica. Também as Corporações Militares e o Estado formularam critérios de avaliação de desempenho que foram transportados para o ambiente empresarial, tanto que do início do século até aproximadamente a Segunda Guerra, as empresas adotavam uma avaliação comportamental e controladora de pessoas, funcionando como um instrumento de punição ou recompensa.

Esta autora mostra que na década de sessenta e setenta, com a intensificação das pesquisas no campo da psicologia, desenvolveram-se inúmeros estudos sobre o comportamento humano no trabalho. $\mathrm{O}$ atual cenário configura um ambiente instável, incerto e cheio de contradições, exigindo da gestão de recursos humanos criatividade e liderança para o processo de mudança. Neste contexto gerenciar desempenho significa descobrir talentos e criar espaços para a ousadia, participação e o comprometimento.

Portanto, é um recurso, utilizado nas empresas, para dimensionamento da qualidade dos seus profissionais. Assim, sua finalidade é identificar o nível de capacitação ou qualificação profissional e o potencial dos seus elementos, analisando esses dados face aos objetivos organizacionais.

De acordo com vários autores, entre eles, AQUINO (1984), BERGAMINI (1983), CHIAVENATO (1987), LUCENA (1991) e MAUDONNET (1988), a avaliação de desempenho tem sido considerada como uma sistemática para a apreciação do desempenho do indivíduo no cargo que ocupa e de seu potencial de desenvolvimento.

Nessa direção, LUCENA (1991) afirma que a preocupação permanente com o desempenho humano e como tornálo mais eficaz é o ponto de atenção máxima, uma vez que a qualidade e efetividade dos resultados organizacionais são conseqüências do desempenho. Estudiosos da administração de recursos humanos têm preconizado a adoção de programas de avaliação de desempenho por parte das empresas.

O Departamento de Enfermagem do Hospital Universitário da Universidade de São Paulo, implantou um sistema de avaliação de desempenho para os integrantes da equipe de enfermagem há 14 anos, ou seja, desde a inauguração do Hospital. A coordenação desse processo é responsabilidade do Serviço de Apoio Educacional (SED).

A avaliação de desempenho é compreendida, pelo Departamento de Enfermagem, como apreciação sistemática do desempenho do indivíduo 
na função que ocupa. Os objetivos determinados para esse processo são: identificar os níveis de desempenho: diagnosticar as necessidades de aperfeiçoamento; oferecer subsídios para a seleção; auxiliar na movimentação quanto a promoções, transferências e desligamentos e favorecer a melhoria da relação interpessoal entre as chefias e seus funcionários.

Para o alcance desses objetivos. 0 Departamento de Enfermagem tem desenvolvido um método de avaliação de desempenho onde todos os elementos da equipe de enfermagem fazem sua autoavaliação e posteriormente, são avaliados por um profissional hierarquicamente superior.

Para isso, avaliados e avaliadores seguem os critérios estabelecidos para a operacionalização desse processo, em relação a: periodicidade da avaliação, escolha e valoração dos prognosticadores e propostas de desenvolvimento do avaliado.

Por ocasião da admissão, todos os funcionários do Departamento de Enfermagem são submetidos a um treinamento admissional, onde são orientados quanto à filosofia, objetivos e aspectos operacionais da avaliação de desempenho.

Ao longo desses anos esse processo sofreu algumas modificações operacionais, mantendo-se inalterado na sua essência. No entanto, tem-se observado uma mudança no clima que permeia a avaliação de desempenho, percebendo-se indícios de insatisfação por parte dos avaliados e avaliadores na condução desse processo. Outro aspecto que sugere necessidade de revisão do instrumento de avaliação é que mesmo os critérios operacionais não têm sido observados.

Autores como KURCGAN'T (1991) descrevem que o instrumento de avaliação tem sido visualizado como um dos componentes mais polêmicos dos programas de avaliação, uma vez que o instrumento registra definitivamente o desempenho e assim representa de forma concreta os resultados da avaliação. Em função disso, muitas vezes o instrumento pode ser tanto elemento de ajuda quanto dificultador da avaliação.

LEVY-LEBOYER (1991) considera também que o processo de avaliação de desempenho depende da pertinência do método e instrumento utilizados para julgar a adptabilidade do indivíduo à função que lhe é atribuída e para avaliar as probabilidades que ele tem de obter êxito na formação ou carreira a que vai ter acesso. Segundo este autor a escolha de um instrumento que permita a descrição do potencial humano e ao mesmo tempo a previsão precisa do comportamento individual em situações de trabalho, é um processo complexo, uma vez que o desempenho humano é resultante de vários fatores como qualidades individuais; situação de trabalho; política de pessoal e mesmo o ambiente exterior à organização.
CIOSAK (1994) ressalta que embora o mais importante na avaliação de desempenho não seja o instrumento nem a técnica, mas a atitude das pessoas envolvidas no processo, tem-se observado que o instrumento de avaliação de desempenho colabora no desenvolvimento do avaliador e do avaliado, ajudando a ambos a externar seus sentimentos ou percepções desagradáveis, muitas vezes protelados se o instrumento não existisse.

Considerando a importância do instrumento de avaliação optamos, neste estudo, por iniciar a análise do processo de avaliação de desempenho da equipe de enfermagem desenvolvido pelo Departamento de Enfermagem do HU, resgatando os resultados das avaliações registradas nesses instrumentos.

Acreditamos que esses registros poderão revelar dados importantes sobre o direcionamento que avaliados e avaliadores têm dado a esse processo.

Pretendemos no futuro ampliar essa análise, voltando a nossa atenção para a percepção dos avaliados e avaliadores, uma vez que o levantamento dos registros da avaliação fornecerão subsídios para essa segunda etapa.

\section{PROCESSO DE AVALIAÇÃO DE DESEM- PENHO DA EQUIPE DE ENFERMAGEM DO HOSPITAL UNIVERSITÁRIO.}

O Departamento de Enfermagem desenvolve o processo de avaliação de desempenho para todos os funcionários de enfermagem no período de experiência e a seguir anualmente ou quando surge alguma intercorrência no desempenho do funcionário a avaliação é feita fora da periodicidade estabelecida. Para tanto utiliza um instrumento de avaliação de desempenho, adota prognosticadores específicos para cada função, com definição e graduação das características selecionadas. Compreende:

1.Definição de termos (Anexo 1): constituído de 15 prognosticadores que apresentam 04 graduações específicas. Para cada categoria funcional estão estabelecidos 05 prognosticadores de avaliação obrigatória, 03 optativos, totalizando 08 ítens em cada avaliação, sendo que os optativos têm como objetivo definir melhor o perfil do funcionário. Cada prognosticador recebe uma graduação (a, b, c ou d) que corresponde a 04 diferentes niveis de desempenho, numa escala crescente de a para $d$. Entretanto, para a avaliação que corresponde ao período de experiência (45 dias) são observados 07 prognosticadores específicos a esse período, que se caracteriza pela adlaptação do funcionário à empresa, não sendo avaliados os ítens determinados para função. 
2. Folha de hetero-avaliação (Anexo 2): apresenta os dados de identificação do avaliado e da avaliação, gráfico para registro de autoavaliação e avaliação, e espaço destinado à anotação da entrevista. A $1^{\circ}$ fase do processo constitui-se na auto-avaliação, onde o avaliado escolhe as graduações e registra no gráfico. Após a auto-avaliação o enfermeiro que supervisionou durante um maior período o trabalho do funcionário, realiza a avaliação e quando necessário devido à complexidade de atividades, rodízios de plantão e de áreas, outros avaliadores participam.

Na avaliação o avaliador deverá:

- considerar o desempenho do funcionário de acordo com o período de avaliação;

- rever as avaliações anteriores, a fim de conhecer o desempenho apresentado anteriormente, analisando o encaminhamento das propostas, reforços e orientações feitas;

- verificar no Caderno de Desempenho, que está destinado ao registro de fatos positivos e negativos referentes a prática diária do desempenho do funcionário, as anotações realizadas no período que compreende a avaliação.

3.Entrevista: após a auto-avaliação e avaliação é realizada a entrevista, onde existe a oportunidade de o avaliador demonstrar o interesse pelo desenvolvimento do funcionário, ouvir suas opiniões, planejando juntos um programa de autoaperfeiçoamento, além de contribuir para melhora das relações interpessoais no ambiente de trabalho. Para tanto o avaliador é orientado a planejar a entrevista, preocupando-se com os seguintes aspectos:

- o que pretende falar;

- como conduzir a entrevista prevendo de acordo com o funcionário, o tipo de reação que ele poderá apresentar;

- os problemas que poderão aparecer e de que maneira isso será trabalhado;

- procurar local reservado, livre de interrupções;

- dar oportunidade para que o avaliado possa falar, discutindo as graduações escolhidas de cada prognosticador;

- citar fatos concretos para exemplificar o desempenho;

- rever com o avaliado- o encaminhamento das propostas das avaliações anteriores, verificando o motivo dos objetivos terem sido atingidos ou não; .

- elaborar, em conjunto com o avaliado, propostas de alteração, orientando-o no que for necessário.
Após a entrevista são registrados pelo avaliador:

- justificativas para a escolha das graduações a e b, com as orientações ou propostas pertinentes;

- justificativas quando houver discordância entre o grau atribuído pelo avaliador e avaliado

- descrição do desempenho relativo aos prognosticadores optativos graduados somente pelo avaliado no gráfico

- postura do funcionário durante a entrevista;

- valorização dos pontos positivos no desempenho do funcionário; andamento do cronograma de orientação específica para funcionários em período de experiência; solicitação do funcionário interessado em transferência de unidade; assinatura do avaliado; avaliador e chefe de seção no final da redação.

\section{OBJETIVOS}

- Verificar se os avaliadores e avaliados seguem os critérios operacionais que norteiam o processo de avaliação de desempenho da equipe de enfermagem do HU.

- Identificar as graduações atribuídas aos prognosticadores obrigatorios e optativos pelos avaliadores e avaliados.

- Identificar os prognosticadores optativos escolhidos pelos avaliadores e avaliados.

- Instrumentalizar os pesquisadores para a reformulação do processo de avaliação de desempenho da equipe de enfermagem do HU.

\section{MATERIAL E MÉTODO}

O trabalho realizado foi um estudo exploratório do tipo documental, uma vez que foram analisadas as informações contidas no instrumento de avaliação de desempenho dos membros da equipe de enfermagem.

\subsection{Local do estudo}

O trabalho foi desenvolvido no Hospital Universitário da Universidade de São Paulo (HU), unidade integrante da Universidade de São Paulo, que faz parte do Sistema Integrado de Saúde. Tem como finalidade promover o ensino, a pesquisa e a extensão de serviços à sociedade.

O HU presta serviços ao corpo docente, discente e servidores da USP; pacientes particulares 
e de convênios, bem como a população pertencente ao Escritório Regional de Saúde (ERSA-2) - Butantã, do Sistema Unificado de Saúde, atuando como referência secundária deste sistema e atendendo as quatro especialidade básicas: clínica geral; cirurgia médica geral; cirurgia geral; pediatria geral e obstetrícia.

Para tanto, dispõe de 242 leitos ativados em unidades de internação, assim distribuídos: Clínica Médica-48 leitos: Clínica Cirúrgica-67 leitos; Clínica Pediátrica-42 leitos; Clínica Obstétrica-53 leitos e Berçário- 32 leitos.

O Departamento de Enfermagem atualmente conta com um contigente de pessoal abrangendo 187 enfermeiros, 41 técnicos de enfermagem e 350 auxiliares de enfermagem. Para garantir a qualidade dos seus recursos humanos o Departamento de Enfermagem conta com o Serviço de Apoio Educacional (SED), o qual é coordenado por uma enfermeira, que tem como responsabilidade as áreas de seleção, treinamento, desenvolvimento e avaliação de desempenho

\subsection{População e Amostra}

Este estudo foi realizado com o instrumento de avaliação de desempenho dos profissionais da equipe de enfermagem contemplando enfermeiros, técnicos e auxiliares de enfermagem. Assim foram selecionadas as avaliações destes profissionais, admitidos no Hospital Universitário, no período de julho de 1985 a julho de 1994. Justifica-se a opção por este período devido a duas situações: a modificação do processo de avaliação de desempenho ter sido realizada em 1985 e a necessidade de se ter avaliações de funcionários com pelo menos um ano de exercício na função, portanto com avaliações de três meses, seis meses e anual.

Dessa forma na fase de coleta de dados, que se deu a partir de agosto de 1995 , o número de funcionários da equipe de enfermagem era de 110 enfermeiros; 24 técnicos de enfermagem e 170 auxiliares de enfermagem, totalizando 304 prontuários com avaliações de desempenho.

A amostragem inicial foi de $30 \%$ dos 304 prontuários, sendo 33 de enfermeiros, 9 de técnicos e 51 de auxiliares de enfermagem. Posteriormente foi modificada em função da análise estatística, constituindo-se em $45 \%$ de enfermeiros (50); $30 \%$ de auxliares (50) e $100 \%$ de técnicos de enfermagem (24).

Para a seleção das amostras foram sorteados os prontuários de cada categoria e em seguida foi sorteada a avaliação de desempenho de cada prontuário selecionado, sendo que foram excluídas as avaliações de 45 dias por serem diferentes os prognosticadores específico para cada função.

\subsection{Instrumento de coleta de dados}

A fonte primária dos dados foram os prontuários dos funcionários que continham as avaliações de desempenho.

Para tanto foi elaborado um instrumento para a coleta de dados (anexo 3) e um memento para auxiliar a obtenção desses dados. $\mathrm{O}$ instrumento foi composto em tres partes, sendo que a primeira diz respeito ao tempo de exercício do funcionário no $\mathrm{HU}$; período de avaliação (3,6 meses ou anual); prazo de entrega da avaliação e retomada do prognosticador, caso este tenha sido graduado em A ou B pelo avaliador na avaliação anterior.

A segunda parte refere-se ao valor atribuído pelo avaliador e avaliado aos prognosticadores obrigatórios e optativos; a terceira parte abrange o registro da entrevista com a descrição do desempenho quanto aos prognosticadores e a última parte contempla as propostas elaboradas pelos avaliadores.

A terceira e quarta parte do instrumento referem-se exclusivamente ao avaliador, uma vez que somente a ele cabe redigir as descrições e proposta em relação ao desempenho do avaliado.

Antes de ser aplicado o instrumento foi realizado um pré teste para as reformulações necessárias.

\subsection{Procedimento para a coleta de dados}

Inicialmente foram levantados os prontuários selecionados, por categoria, pelo Serviço de Apoio Educacional, sendo sorteados os prontuários em igual número para cada pesquisadora. Posteriormente cada elemento verificou o número de avaliações de desempenho contidas em cada prontuário, selecionando uma avaliação de desempenho por meio de sorteio, aplicando então o instrumento elaborado.

\section{APRESENTAÇÃO E DISCUSSÃO DOS RESULTADOS}

A caracterização dos sujeitos deste estudo demonstrou que a maioria dos enfermeiros, técnicos e auxiliares de enfermagem trabalham há mais de dois anos no Hospital Universitário e com isso possuem larga experiência no processo de avaliação de desempenho. Apesar de não termos coletado o tempo de vivência dos avaliadores no Hospital Universitário é critério que os enfermeiros com menos tempo de trabalho no $\mathrm{HU}$, realizem a avaliação dos funcionários junto a um enfermeiro com maior experiência neste processo, portanto podemos inferir que os avaliadores também 
possuíam o mínimo de prática nesta área. Entretanto, observamos que os avaliadores não realizam as avaliações no prazo previsto. A maioria das avaliações que são entregues no prazo, são de enfermeiros.

Sobre este fato LUCENA (1992), comenta que estes prazos consistem no dia fatal da devolução do instrumento de avaliação, o qual o avaliador recebeu no mês anterior. Muitas vezes, segundo esta autora, o não cumprimento do prazo se deve ao fato do avaliador visualizar a avaliação dos seus funcionários como uma tarefa burocrática e o preenchimento dos formulários, um ritual quase sempre condicionado pelos últimos acontecimentos.

Ainda verificamos que a maioria dos avaliadores retomam em suas avaliações, os prognosticadores que nas avaliações anteriores, atribuíram os valores A e B. De acordo com SACHS (1995) embora o acompanhamento seja importante para todos os funcionários, ele se mostra crucial quando se trata de alguém que tenha desempenho insatisfatório. Por meio da retomada desse prognosticadores o avaliador identifica se houve melhora no desempenho do funcionário, se as propostas foram implantadas, comparando o desempenho anterior com o atual.

Neste estudo observamos que tanto os avaliadores como avaliados atribuíram, em sua grande maioria, graus C e D para os prognosticadores obrigatórios e optativos, nas três categorias, isto é, enfermeiro, técnico e auxiliar de enfermagem. Isto demonstra que os avaliadores consideram que os avaliados possuem um padrão de desempenho esperado porque já na avaliação de quarenta e cinco dias é discutido com o funcionário os pontos negativos do seu desempenho e na de três meses se não houver melhora no desempenho, este funcionário não é aceito na instituição. Outra situação que pode indicar a atribuição dos graus C e $\mathrm{D}$, é o processo seletivo, que propicia a escolha de funcionários que melhor se adaptam a esta organização.

No que diz respeito a concordância e discordância entre avaliadores e avaliados, constatamos nas avaliações das três categorias um índice maior de concordância entre avaliadores e avaliados, tanto para prognosticadores obrigatórios como optativos. Este resultado era esperado uma vez que a grande maioria dos avaliadores e avaliados, conforme acima citado, atribuíram os graus C e D. SACHS (1995) refere que quando o funcionário é sincero em sua auto avaliação, não deverá haver muita disparidade entre ele e o avaliador. Considera que na maioria das vezes o funcionário atribui a si valores maiores que o avaliador, que é quem é capaz de observar o que o funcionário deixa a desejar no seu trabalho. A afirmação deste autor vai de encontro com os resultados encontrados neste estudo, uma vez que em algumas situações, principalmente para a categoria enfermeiro e auxiliar de enfermagem a discordância entre avaliador e avaliado ocorreu quando o avaliador atribuiu um grau menor que o avaliado.

Acreditamos que também este alto índice de concordância entre os avaliadores e avaliados é consequência dos funcionários terem conhecimento do processo de avaliação desde o momento da sua admissão, estan do familiarizado com o instrumento utilizado. Outro fator que leva a esse alto índice de concordância pode ser atribuído a forma participativa do processo, que de acordo com SACHS (1995) propicia o consenso entre avaliador e avaliado a respeito das atribuições mais importantes do cargo ocupado, assim como da importância relativa de cada prognosticador. Dessa forma segundo este autor se há grande divergência de opiniões nesta área, fica claro que existem problemas significativos entre o funcionário e o avaliador.

Em relação especificamente aos prognosticadores optativos, evidenciou-se que para a categoria enfermeiro, os mais escolhidos pelos avaliadores e avaliados foi Interesse para o trabalho e o menos escolhido foi respectivamente Pontualidade e Criatividade. Para a categoria Técnico de Enfermagem os avaliadores escolheram Disponibilidade para o trabalho e os avaliados Aceitação de Orientação, sendo que o prognosticador Capacidade de Liderança não foi selecionado por ambos sujeitos. E para os Auxiliares de Enfermagem, tanto os avaliadores e avaliados escolheram com maior frequência o prognosticador Organização no Serviço e Capacidade de Liderança não foi selecionado por eles.

KURCGANT (1991) considera importante a opção por prognosticadores, uma vez que eles delineiam o perfil profissional do elemento a ser avaliado, sendo que entre eles encontramos os que se referem a atividades propriamente ditas e outros a fatores pessoais. Dessa forma, para enfermeiros e técnicos de enfermagem, a opção maior foi para prognosticadores pessoais e para os auxiliares o profissional

Em relação à liderança, ressaltamos que não houve opção por este prognosticador na avaliação dos técnicos e auxiliares de enfermagem o que nos leva a concluir que ele não é considerado como um atributo dessas funções.

Quanto as descrições observamos que para a categoria dos enfermeiros todas as avaliações cujos prognosticadores obrigatorios receberam os graus A e B tinham descrições, evidenciando que os avaliadores atenderam integralmente o critério que preconiza quando o avaliador atribui essa graduação, necessariamente tem que haver 
descrição. Entretanto o mesmo não ocorreu em relação as categorias técnico e auxiliar de enfermagem Isso corrobora com os dados encontrados por KURCGANT( 1991), em que os enfermeiros sentem-se mais seguros quando avaliam outros enfermeiros.

Porém quando os avaliadores realizaram essas descrições, o conteúdo foi apenas a repetição da definição do prognosticador segundo o grau atribuído como exemplificamos a seguir:

- Capacidade de detectar problemas e iniciativa para resolvê-los: funcionária apresenta dificuldade de dar soluções a problemas que possam intervir no andamento da únidade;

- Pontualidade: as vezes apresenta falha na pontualidade;

- Aceitação de orientação: aceita orientação porém não as cumpre conforme orientação, sendo que já foi discutido com a mesma. Não segue normas disciplinares;

- Capacidade de relacionamento paciente e família: certa dificuldade em relacionar-se com paciente e família;

- Capacidade de liderança: necessidade de melhorar a liderança frente ao grupo de trabalho;

- Organização da Unidade: não se preocupa com a organização da unidade;

- Interesse para o trabalho: demonstra interesse apenas pelas tarefas que lhe são atribuidas;

Observamos ainda que o fato acima relatado também ocorre quando os avaliadores realizaram descrições para os graus C e D, exemplificados nas seguintes avaliações:

- Responsabilidade: desenvolve o seu trabalho com responsabilidade;

- Postura física: tem uma postura muito boa com os funcionários;

- Capacidade de trabalhar em equipe: mantém bom relacionamento com a equipe multiprofissional.

SACHS (1995) mostra a importância do avaliador descrever o desempenho do avaliado principalmente em relação as deficiências, pois ao relatar os fatos e as situações críticas evidencia os pontos sobre os quais o avaliado necessita modificar o seu desempenho. Faz a ressalva que para o avaliador é muito desagradável descrever o comportamento de um funcionário com desempenho deficiente, principalmente quando relacionados com atitudes consideradas prejudiciais ao desenvolvimento da função. Também BERGAMINI (1981) afirma que avaliar é uma tendência humana, mas dizer o que se pensa sobre alguém e ainda escrevê-lo não se constitui em uma necessidade fundamental, uma vez que as consequências podem causar problemas tanto ao avaliador como avaliado, portanto é normal que cada um tente evitar todos os problemas que lhe dificultem a vida.

Provavelmente estes fatos possam explicar porque os avaliadores não realizaram descrições para todas as situações em que o desempenho do avaliado não foi favorável ou quando as fazem se utilizam de rótulos que não demonstram o desempenho efetivo do funcionário.

Por outro lado, no que diz respeito as propostas, onde a regra preconiza que para os graus A e B, o avaliador também tem que elaborar proposta, ficou evidenciado que para todas as categorias esta norma não foi respeitada, apontando que o menor índice de propostas foi para os auxiliares de enfermagem. Também em muitas avaliações as propostas redigidas tiveram caráter de orientações tais como:

- Capacidade de liderança: orientada sobre a necessidade de controlar a ansiedade;

- Organização no Serviço: orientada sobre a necessidade de planejar as suas atividades diárias priorizando as atividades mais relevantes, objetivando a qualidade da assistência prestada.

- Organização no Serviço: orientada quanto a importância de manter em ordem os materiais $e$ equipamentos da unidade.

De acordo com SACHS (1995) as propostas talvez se constituem na etapa mais importante do processo de avaliação, sendo muitas vezes completamente esquecidos ou pouco discutidos. Isto porque as propostas consistem na elaboração de metas a serem atingidas a curto e médio prazo, sendo uma forma do avaliado sentir-se valorizado por reconhecer que o avaliador está preocupado com suas necessidades e mesmo os melhore funcionários devem ter novas metas pelas quais lutar. E nas próximas avaliações os progresso obtidos são avaliados em comparação com as metas definidas, assim avaliador e avaliado decidem juntos se os planos estratégicos do funcionário devem ser alterados e qual a melhor forma de fazê-lo.

Concordamos com este autor quando diz que o resultado mais importante da avaliação de desempenho não é a classificação de desempenho do avaliado; mas o fato de avaliador e avaliado discutirem juntos as propostas de desenvolvimento, fortalecendo seu relacionamento e formando uma equipe composta de pessoas que trabalham de comum acordo em direção a uma mesma meta.

Correlacionando as duas normas relativas a descrição e proposta com os prognosticadores optativos ficou demonstrado que para as três categorias, as mesmas não foram cumpridas 
integralmente, uma vez, que não foram todos os avaliadores que realizaram descrição e propostas quando atribuíram os valores A e B aos avaliados.

Quanto a norma que estabelece que haja descrição quando houver discordância em relação ao grau atribuído pelo avaliador e avaliado tanto para os prognosticadores obrigatórios como optativos, não foi cumprida para as três categorias.

Ainda em relação ao critério que preconiza que para os prognosticadores optativos selecionados somente pelo avaliado, o avaliador tem que obrigatoriamente realizar a descrição, identificamos que para as três categorias, os avaliadores não cumpriram na íntegra esta norma.

Assim pelo acima exposto quanto a conduta dos avaliadores em relação as descrições e propostas relativas ao desempenho dos funcionários, identificamos que os avaliadores ou não valorizam estes aspectos no processo de avaliação ou então têm dificuldade para desenvolvê-lo, o que pode ser indicativo de falhas no preparo do avaliador.

Em relação ao preparo do avaliador LUCENA (1992) coloca que muitas vezes as instituições cometem um equívoco, quando partem do pressuposto que para desenvolver o avaliador, é suficiente ensinar o ritual do preenchimento do formulário de avaliação, acrescentado de alguns conselhos sobre habilidades gerenciais necessárias para aplicar o processo. Este preparo vai mais além, configurando-se numa ação mais ampla que significa o desenvolvimento do avaliador como um todo, tendo com clareza a natureza dos objetivos do processo de avaliação de desempenho dentro da instituição.

Dessa forma concordamos com MAYA (1993) quando se refere a avaliação de desempenho como um instrumento para o processo de qualidade total de um serviço, tendo como referencial o crescimento e desenvolvimento do funcionário, entendendo este funcionário como avaliado e avaliador.

\section{CONSIDERAÇÕES FINAIS}

Este estudo demonstrou que apesar dos sujeitos terem diferentes posições e categorias funcionais dentro do processo de avaliação de desempenho, existem pontos convergentes, uma vez que houve um alto grau de concordância entre eles tanto na atribuição de valores, como na seleção de prognosticadores optativos. Este fato demonstra que há uma coerência no processo de avaliação de desempenho da equipe de enfermagem do HU, revelando que avaliadores e avaliados compartilham dos mesmos pressupostos quanto a finalidade e importância dos prognosticadores inseridos no instrumento de avaliação de desempenho.
$\mathrm{O}$ aspecto mais importante revelado nesta pesquisa diz respeito ao preparo do avaliador que demonstrou dificuldade em descrever objetivamente os problemas de desempenho dos avaliados, bem como de elaborar propostas que favoreçam o desenvolvimentos dos mesmos.

Portanto a atual preocupação dos pesquisadores deste estudo é em relação a questão do preparo do avaliador quanto a sua capacitação para descrever e elaborar propostas referentes aos prognosticadores, de forma a se ter uma visão integrada do desempenho do funcionário. Para tanto estamos elaborando um novo projeto, com o objetivo de investigar junto aos avaliadores suas dificuldades para elaborar descrições e propostas quanto ao desempenho do funcionário e de posse destes resultados desenvolver um progama de capacitação

Esperamos que os resultados descritos possam de alguma forma contribuir para a maior conscientização dos enfermeiros quanto à aplicação do processo de avaliação de desempenho no aprimoramento da enfermagem não so do Hospital Universitário da USP como em geral, incluindo o ensino de enfermagem

\section{REFERÊNCIA BIBLIOGRÁFICA}

AQUINO, C.O. Administração de recursos humanos: uma introdução. São Paulo, Atlas, 1984.

BERGAMINI, C.W. Avaliação de desempenho humano na empresa. 3.ed. Såo Paulo, Atlas, 1981.

CHIAVENATO, I. Administração de recursos humanos. 2.ed. São Paulo, Atlas, 1987. v. 2.

CIOSAK, S. I. Avaliação de desempenho e o aprimoramento de enfermeiros: expectativas do avaliador e avaliado. São Paulo. 1994. 127p. Tese (Doutorado) - Escola de Enfermagem, Universidade de São Paulo.

KURCGANT, P. Avaliação de desempenho do pessoal de enfermagem. In: Administração em enfermagem. São Paulo, EPU, 199 1. cap. 11, p. 133 -45.

LEVY-LEBOYER, C. Avaliação do pessoal na empresa Lisboa, Editora Presença, 1991.

LUCENA, M. D. da S. Planejamento de recursos humanos. São Paulo, Atlas, 1991.

LUCENA, M.D. da S. Avaliação de desempenho. São Paulo, Atlas, 1992.

MAUDONNET, R. Administração Hospitalar. Rio de Janeiro, Cultura Médica, Rio de Janeiro, 1988.

MAYA, M.C.M. Evaluacion del desempeno y su efecto en la calidad total. Invest. Educ. Enf., v. 11, n. 2, p. 50-8, 1993.

PINTO, E.P. Multianálise do desempenho e do potencial. São Paulo, STS, 1995.

SACHS, R.T. Como avaliar o desempenho e a produtividade. Rio de Janeiro, Campus, 1995 


\section{ANEXO 1 \\ DEPARTAMENTO DE ENFERMAGEM \\ SERVIÇO DE APOIO EDUCACIONAL \\ ITENS PARA AVALIAÇÃO DE DESEMPENHO}

\section{Atenção:}

- Não rasure esta folha

As anotações e observações devem ser feitas na folha de hetero-avaliação

\section{DEFINIÇÃO DE TERMOS}

01. Capacidade de liderança: é a facilidade com que comanda, orienta e mantém sua autoridade diante dos subordinados, promovendo o equilíbrio do grupo, fazendo-o desenvolver-se no trabalho e crescer profissionalmente.

a) falta-lhe recursos pessoais para exercer liderança, seu comportamento faz com que seja reconhecido como líder institucional e não natural.

b) falta-lhe recursos pessoais para exercer liderança, mas esta preocupado em desenvolver-se nesse aspecto.

c) tem recursos pessoais de líder e, de forma geral, assume perante seus subordinados um comporta-mento que inspira respeito e aceitação.

d) tem recursos pessoais de líder e consegue, com naturalidade, fazer com que seus subordinados o respeitem e acatem suas determinações.

02. Capacidade de trabalhar em equipe: é a facilidade com que o avaliado consegue relacionar-se com os membros de sua equipe.

a) cria dificuldade por causa da forma inadequada com qual se dirige aos demais elementos da equipe.

b) esforça-se por estabelecer bom contato com os demais membros da equipe, mas ainda não consegue desenvolver um relacionamento profissional adequado.

c) mantém um bom relacionamento profissional com todos os membros da equipe.

d) mantém um bom relacionamento profissional, colaborando na promoção da união da equipe.

03. Conhecimento de procedimentos: é saber as normas e técnicas estabelecidas na instituição para a execução do seu trabalho.

a) não conhece muitos dos procedimentos sob sua responsabilidade.

b) conhece, de maneira geral, os procedimentos sob sua responsabilidade porém, quando em dificuldade, nem sempre solicita orientação.

c) conhece, de maneira geral, os procedimentos sob sua responsabilidade e, quando em dificuldade, solicita orientação espontaneamente.

d) conhece os procedimentos sob sua responsabilidade e consegue adaptá-los, quando necessário, sem ferir os princípios científicos.

04. Responsabilidade: é a maneira consciente com a qual desempenha suas funções, respondendo legal e moralmente pelos seus atos. 
a) não desempenha suas funções de maneira consciente.

b) não desempenha suas funções de maneira consciente, a menos que se sinta supervisionado.

c) é consciente de suas funções, embora eventualmente precise sex lembrado pelo supervisor das tarefas que lhe são confiadas.

d) assume suas responsabilidades e tarefas.

05. Capacidade de relacionamento com o paciente/família: é a capacidade de entender o paciente/família e de se fazer entender por ele.

a) tem dificuldade em entender o paciente/família e em se fazer entender por ele

b) esforça-se por entender o paciente/família mas ainda não consegue desenvolver um relacionamento adequado.

c) apresenta facilidade de relacionamento com o paciente/família, reconhecendo de modo geral suas necessidades e fazendo-as entender nas orientações.

d) possui otimo relacionamento com o paciente/família, fazendo-se entender facilmente nas orientações.

06. Assiduidade: é o comparecimento regular do funcionário ao local onde desempenha suas funções.

a) falta ao serviço e nem sempre justifica ou suas justificativas não são aceitáveis.

b) falta ao serviço e suas justificativas são aceitáveis.

c) raramente falta ao serviço.

d) não falta ao serviço.

07. Pontualidade: é o comparecimento do funcionário à hora marcada na unidade de trabalho.

a) chega freqüentemente após as passagens de plantão.

b) chega freqüentemente durante as passagens de plantão.

c) é pontual, atrasando-se raramente para as passagens de plantão.

d) não se atrasa para as passagens de plantão.

08. Criatividade: é a capacidade de sugerir mudanças a partir dos recursos disponíveis e princípios préestabelecidos, enriquecendo a rotina de trabalho.

a) acomodou-se na forma já conhecida de trabalho.

b) ocasionalmente sugere mudanças na rotina de trabalho, porêm nem sempre são eficazes.

c) ocasionalmente sugere mudanças que enriquecem a rotina de trabalho.

d) freqüentemente sugere mudanças que enriquecem a rotina de trabalho.

09. Interesse para o trabalho: é o desenvolvimento do indivíduo em seu trabalho.

a) é um indivíduo pouco interessado pelas tarefas que lhe são atribuídas. 
b) demonstra interesse apenas pelas tarefas que lhe são atribuidas.

c) interessa-se por seu trabalho, mostrando boa vontade no desempenho de suas tarefas em busca de melhores níveis de atuação.

d) demonstra envolvimento com as atividades da unidade e participa efetivamente dos eventos científicos e educacionais.

10. Aceitação de orientação: é como o funcionário acata e cumpre as orientações disciplinares ou de serviço.

a) não aceita as orientações.

b) acata as orientações porém não as cumpre conforme foi orientado.

c) aceita as ordens de serviço e normas disciplinares que recebe.

d) assume as orientações recebidas transmitindo-se aos demais quando necessário.

11. Comunicacão oral e escrita: é a habilidade de se fazer entender, escrita ou verbalmente.

a) cria problemas por falta de habilidade em se fazer entender pelos demais.

b) tem dificuldades em expressar suas idéias escrita ou verbalmente.

c) tem dificuldade em expressar suas idéias escrita ou verbalmente, porém tem demonstrado esforço para melhorar.

d) tem boa comunicação escrita e verbal.

12. Capacidade de detectar problemas e iniciativa para resolvế-los: é a capacidade de perceber situações problemáticas e propor soluções adequadas.

a) apresenta dificuldade em perceber situações problemáticas.

b) percebe situações problemáticas, porém não é capaz de dar soluções adequadas.

c) percebe situações problemáticas, porém não é capaz de dar soluções adequadas.

d) percebe situações problemáticas e consegue dar soluções adequadas, de forma rápida mesmo em situações de maior complexidade.

13. Organizado no serviço: é a facilidade em ordenar desenvolver e manter o trabalho de maneira racional.

a) é desorganizado chegando a comprometer o andamento e a boa execução do serviço. Traz dificuldades para quem depende de suas atividades.

b) executa seu trabalho de forma relativamente organizada, não chegando a trazer dificuldade para quem depende de suas atividades.

c) é organizado e trabalha de forma racional.

d) mantém o trabalho organizado conseguindo sugerir melhores métodos na execução do mesmo.

14. Postura física: é a maneira de se apresentar, modo de sentar, falar e agir no desempenho de suas atividades profissionais. 
a) sua postura não é adequada à função que desempenha

b) apresenta falhas na postura que assume no desempenho de sua função.

c) apresenta falhas na postura que assume no desempenho de sua função, mas se preocupa em melhorar.

d) sua postura é adequada à função que desempenha.

15. Disponibilidade para o trabalho: é o empenho em conciliar sua vida particular com as necessidades do serviço.

a) não demonstra empenho em conciliar sua vida particular com as necessidades do serviço.

b) demonstra empenho em conciliar sua vida particular com as necessidades do serviço, embora nem sempre consiga

c) concilia sua vida particular com as necessidades do serviço.

d) concilia sua vida particular com as necessidades do serviço, se dispondo a atividades não previstas.

\section{ANEXO 2}

Departamento de Enfermagem

Serviço de apoio educacional

Folha de hetero - avaliação

Identificação do avaliado

Nome: $\mathrm{N}^{\circ}$ de Prontuário

Período de avaliação: à

Data de Emissão da Folha: Devolução em

Auto avaliação e avaliacão

Auto-Avaliação:

Data:

\begin{tabular}{|l|l|l|l|l|}
\hline $\begin{array}{c}\text { Grau } \\
\text { Itens }\end{array}$ & A & B & C & D \\
\hline & & & & \\
\hline & & & & \\
\hline & & & & \\
\hline & & & & \\
\hline & & & & \\
\hline & & & & \\
\hline & & & & \\
\hline & & & & \\
\hline
\end{tabular}

Entrevista de avaliação
Avaliação:

Data:

\begin{tabular}{|l|l|l|l|l|}
\hline $\begin{array}{c}\text { Grau } \\
\text { Itens }\end{array}$ & A & B & C & D \\
\hline & & & & \\
\hline & & & & \\
\hline & & & & \\
\hline & & & & \\
\hline & & & & \\
\hline & & & & \\
\hline & & & & \\
\hline & & & & \\
\hline
\end{tabular}




\section{ANEXO 3}

\section{INSTRUMENTO DE COLETA DE DADOS}

01 - Função:

Enfermeiro

Técnico de Enfermagem

Auxiliar de Enfermagem

02- Unidade:

03 - Tempo de exercício da função:

04 - Avaliação sorteada:

$$
\begin{aligned}
& 33=03 \text { meses } \\
& 34=06 \text { meses } \\
& 35=\text { anual }
\end{aligned}
$$

05 - Prazo - $n^{0}$ de dias:

06 a 13 - Folha anexa.

14 - Outros registros:

15 - Retomada dos prognosticadores problema da avaliação anterior.

$$
\begin{aligned}
& 1=\operatorname{Sim} \\
& 2=\text { Não } \\
& 3=\text { Não pertinente }
\end{aligned}
$$




\section{PROGNOSTICADORES OBRIGATÓRIOS}

\begin{tabular}{|c|c|c|c|c|c|}
\hline \multicolumn{4}{|c|}{ Gráfico } & \multicolumn{2}{|c|}{ Registro da entrevista } \\
\hline 6 & Denominação & \multicolumn{2}{|c|}{ Grau } & 12 Descrição & 13 Proposta \\
\hline Ordem & & 7 Auto & 8 Aval. & Do Desempenho & \\
\hline & & & & & \\
\hline & & & & & \\
\hline & & & & & \\
\hline & & & & & \\
\hline & & & & & \\
\hline & & & & & \\
\hline
\end{tabular}

